Check for updates

Cite this: RSC Adv., 2017, 7, 37990

Received 20th April 2017

Accepted 17th July 2017

DOI: $10.1039 / c 7 r a 04459 c$

rsc.li/rsc-advances

\section{Biofouling formation and structure on original and modified PVDF membranes: role of microbial species and membrane properties}

\begin{abstract}
Guili Zhao (iD) abc and Wei Ning Chen*c
In our previous study, three types of modified PVDF membranes, PVDF-g-PHEMA, PVDF-g-PNIPAAm, and PVDF-g-P(HEMA-Co-NIPAAm), were successfully prepared by grafting the functional polymers PHEMA and PNIPAAm. In this study, bacterial adhesion tests on the original and modified PVDF membranes were performed using two model microbial species, i.e. Gram-negative Escherichia coli and Gram-positive Staphylococcus epidermidis, to investigate the effect of microbial species and membrane properties on the formation and structure of biofouling. The results indicated that less biofouling was found on the modified membranes as compared to that on the original membrane in both mono-species tests and mixed-species tests; this finding confirmed that the hydrophilicity of the membrane significantly affected the formation of biofouling such that the antifouling properties of the PVDF membranes were remarkably enhanced after grafting of the hydrophilic polymers on them. Less biofouling was observed on the modified hydrophilic membranes, with scattered biofouling spots for mono-species, whereas a thin layer structure of biofouling was observed for mixed-species; however, heavy biofouling covered the original membrane with a thick cake layer for both mono-species and mixed-species. This demonstrated that the microbial species significantly affected the formation and structure of biofilms since the species influenced the bacterial adhesion and biofouling behavior of each other based on their type and characteristics; moreover, the hydrophilicity of membrane also displayed an essential effect on the biofouling structure. The novelty of this study is as follows: it demonstrates that the microbial species and membrane properties play an essential role in the biofouling formation and structure as well as how to influence biofouling on different membranes; this study can provide useful insight and indications on how to effectively control and inhibit biofouling in the future.
\end{abstract}

\section{Introduction}

Membrane bioreactors (MBRs) are considered as a promising technology in wastewater treatment applications due to their several advantages such as a small footprint, less sludge production, and higher effluent quality as compared to the conventional-activated sludge systems. ${ }^{1-3}$ However, there still exist several challenges for the wider application and faster development of the MBR technology. One of the major obstacles that limits the potential of this technology is membrane fouling, which significantly reduces the filtration flux, shortens the lifespan of the membrane, and increases energy

\footnotetext{
${ }^{a}$ Nanyang Environment and Water Research Institute, Interdisciplinary Graduate School, Nanyang Technological University, 1 Cleantech Loop, Singapore 637141, Singapore

${ }^{b}$ Advanced Environmental Biotechnology Centre, Nanyang Environment and Water Research Institute, Nanyang Technological University, 1 Cleantech Loop, Singapore 637141, Singapore

${ }^{c}$ School of Chemical and Biomedical Engineering, Nanyang Technological University, 62 Nanyang Drive, Singapore 637459, Singapore. E-mail: WNChen@ntu.edu.sg; Tel: $+6563162870$
}

consumption and overall costs. ${ }^{4,5}$ Membrane fouling is mainly caused by the deposition of inorganic and organic substances on the membrane surface and its pores, wherein microorganisms and microbial foulants contribute to the formation of biofouling/biofilms. In a previous study, it was demonstrated that biofilms formed on a microfiltration membrane under observation via confocal laser scanning microscopy (CLSM), which resulted in a decline of system performance. ${ }^{6}$

It is known that the formation of biofilms starts with the early attachment of bacteria and their subsequent proliferation on the substrate surface, ${ }^{7}$ wherein the microorganisms usually produce extracellular polymeric substances (EPSs), which are responsible for the growth and adhesion of microorganisms on the surface. ${ }^{8,9}$ It has been reported that the species and characteristics of microorganisms, for example, their different cell walls and composition of the EPSs produced, and the microbial community affect the formation of biofilms by affecting the interactions with the membrane material. ${ }^{10,11}$ In a study reported by Dreszer et al., ${ }^{12}$ the development of the formation, structure, and detachment of biofilms was investigated via optical coherence tomography (OCT) to discover their relation 
with the transmembrane pressure and membrane performance. The results indicated that an increase in biofilm thickness played an important role in decline of membrane performance, whereas biofilm thickness decreased with an increase in permeate flux, leading to a denser structure. These phenomena demonstrated that both the thickness and the structure of biofilms affected the membrane performance. Moreover, different types of membranes had a significant effect on the biofouling behavior owing to different properties of the membranes. A previous study ${ }^{\mathbf{1 3}}$ indicated that the hydrophilicity of a membrane significantly influenced the maturation and structure of biofouling, wherein uniform and thin biofilms were rapidly deposited on a hydrophobic polyvinyl difluoride (PVDF) membrane, whereas bacterial attachment was resistant to occur on the hydrophilic surface of the polyvinyl alcohol (PVA) membrane. Therefore, it is necessary to investigate the effect of microbial species and the properties of the supporting membrane on the formation and structure of biofouling for the control and removal of unwanted biofouling.

Currently, the development of antifouling membranes is considered as one of effective strategies to reduce membrane fouling. In our previous study, ${ }^{\mathbf{1 4}}$ the functional polymers poly(hydroxyethyl methacrylate) (PHEMA) and $\operatorname{poly}(N$-isopropylacrylamide) (PNIPAAm) were utilized to modify a PVDF membrane to improve its antifouling properties owing to their high resistance to protein adsorption and bacterial adhesion, which led to the formation of PVDF- $g$-PHEMA, PVDF- $g$-PNIPAAm, and PVDF- $g$-P(HEMA-co-NIPAAm) membranes. In particular, PNIPAAm, which is a typical thermosensitive polymer, exhibited biofouling release properties in response to changes in temperature; this was due to change in the hydrophilicity at the lower critical solution temperature (LCST) of around $32{ }^{\circ} \mathrm{C}$. The preliminary results indicated that the hydrophilicity of the PVDF membrane was significantly improved after the functional polymers were grafted, and the antifouling properties of the modified membranes were remarkably enhanced in comparison with those of the pure PVDF membrane. In particular, PVDF- $g$-P(HEMA-co-NIPAAm) exhibited better resistance ability to protein adsorption and bacterial adhesion among the modified membranes. It was reported that the high complexity of microbial communities in activated sludge systems had a significant effect on the antifouling efficiency and it increased the difficulty of the study. ${ }^{\mathbf{1 5}}$ Therefore, it is very important to investigate the effect of microbial species and the properties of the supporting membrane on the formation of biofilms and their structure. This study was aimed at investigating biofouling on the original PVDF membrane and three types of modified membrane prepared in our laboratory and revealing the effect of microbial cells on the formation and structure of biofouling using two types of well-studied model organisms. Hence, it can provide indications on how to effectively control and inhibit biofouling in the future, which is one of the novelties of this study. Furthermore, dynamic filtration experiments were also conducted using a microbial suspension and synthetic wastewater-containing proteins and humic acid to evaluate the antifouling properties of the membranes and confirm the great potential of the modified membranes for practical wastewater treatment.

\section{Experimental}

\section{Materials}

A commercial PVDF membrane (diameter: $50 \mathrm{~mm}$; average pore size: $0.45 \mu \mathrm{m}$ ) was provided by ACME Research Support Pte Ltd., Singapore. The commercial PVDF membrane was used as a base matrix for surface modification, and three types of modified membrane, i.e. PVDF- $g$-PHEMA, PVDF- $g$-PNIPAAm, and PVDF- $g$-P(HEMA-co-NIPAAm), were prepared according to our previous study. ${ }^{14}$ Bovine serum albumin (BSA, $>99 \%, M_{\mathrm{n}}=$ $67 \mathrm{kDa}$ ) and humic acid were supplied by Chemicals Testing \& Calibration Laboratory Pte Ltd., Singapore. The dye SYTO 63 was purchased from Thermo Fisher Scientific Life Technologies Holdings Pte Ltd., Singapore. LIVE BacLight ${ }^{\mathrm{TM}}$ Bacterial Gram Stain Kit L7005, which contained two dyes SYTO 9 and hexidium iodide, was also purchased from Thermo Fisher Scientific Life Technologies Holdings Pte Ltd., Singapore.

\section{Antibacterial activity and biofouling release test}

To evaluate the fouling resistance of the modified membranes to different bacterial strains, their antimicrobial activity was determined via bacterial adhesion on the membrane surface using the typical Gram-negative bacterium Escherichia coli $^{\mathbf{1 6}}$ and the Gram-positive bacterial strain Staphylococcus epidermidis. ${ }^{\mathbf{1 7}}$ The protocol was adapted from our previous study. ${ }^{\mathbf{1 4}}$ In detail, $E$. coli was cultured in a flask with an LB medium, which consisted of $10 \mathrm{~g} \mathrm{~L}^{-1}$ tryptone, $5 \mathrm{~g} \mathrm{~L}^{-1}$ yeast extract, and $10 \mathrm{~g} \mathrm{~L}^{-1}$ sodium chloride. The bacteria were cultured in an incubator for $5 \mathrm{~h}$ at $37^{\circ} \mathrm{C}$ at a shaking speed of $200 \mathrm{rpm}$, and finally, the cell concentration was approximately $10^{9}$ cells per mL. Membrane samples were placed in a $5 \mathrm{~mL}$ bacterial suspension in a 6-well plate for $5 \mathrm{~h}$ at $25^{\circ} \mathrm{C}$ and $37^{\circ} \mathrm{C}$. After this, the membranes were washed using a $0.01 \mathrm{M}$ phosphate buffered saline (PBS) solution, and bacterial cells deposited on the membrane surface were observed via SEM (JSM-6701F, JEOL Asia Pte. Ltd.) according to the previous literature..$^{18,19}$ The amount of bacterial adhesion on the membrane surface was determined by counting the bacterial cells from the SEM images within a certain area (at least 8 SEM images). In the Gram-positive bacteria test, $S$. epidermidis was cultured in a YPD (yeast extract-peptonedextrose) medium containing $10 \mathrm{~g} \mathrm{~L}^{-1}$ yeast extract, $20 \mathrm{~g} \mathrm{~L}^{-1}$ peptone and $20 \mathrm{~g} \mathrm{~L}^{-1}$ dextrose at a shaking speed of $200 \mathrm{rpm}$ at $37{ }^{\circ} \mathrm{C}$. After incubation for $5 \mathrm{~h}$, the cell concentration reached $10^{9}$ cells per $\mathrm{mL}$. The next step of the bacterial adhesion experiment was similar to that used for the E. coli strain.

The bacterial release properties of the membranes with respect to different bacterial species were also assessed via a colony forming unit (CFU) test using $E$. coli and $S$. epidermidis..$^{\mathbf{2 0} 21}$ Specifically, as abovementioned in the antibacterial activity test, the membrane samples were immersed in a $5 \mathrm{~mL}$ E. coli suspension for incubation for $5 \mathrm{~h}$ at $37^{\circ} \mathrm{C}$. After this, the samples were taken out and slightly rinsed with a sterile PBS solution. Then, parallel samples of the same 
membrane were placed in a $5 \mathrm{~mL}$ sterile PBS solution for bacterial detachment for further $5 \mathrm{~h}$ at $25{ }^{\circ} \mathrm{C}$ and $37{ }^{\circ} \mathrm{C}$. After this, the remaining bacterial cells adhering to the membranes were thoroughly obtained by rinsing, and the cleansed solution was diluted 100-fold. Then, $0.1 \mathrm{~mL}$ of the diluent was inoculated onto an LB agar plate for culture for $15 \mathrm{~h}$ at $37^{\circ} \mathrm{C}$. The $\mathrm{CFU}$ number of bacteria obtained from the membrane after detachment for $5 \mathrm{~h}$ at different temperatures was used to evaluate the biofouling release properties. The CFU tests were performed using 3 independent samples for each measurement, and each measurement was carried out on 3 replicate agar plates. For the Gram-positive bacteria test, note that S. epidermidis was cultured in a YPD medium, and the cleansed solution was diluted 1000 -fold in the biofouling release test.

\section{Biofilm analysis using confocal laser scanning microscopy}

To study the formation and construction of biofilms caused by the Gram-negative bacteria or Gram-positive bacteria, the biofilms of $E$. coli or $S$. epidermidis on the membrane surface were also visualized and analyzed by confocal laser scanning microscopy (CLSM). The biofilms were formed after the deposition of bacteria on the membranes for $12 \mathrm{~h}$ at $25^{\circ} \mathrm{C}$ and $37^{\circ} \mathrm{C}$, and this process was the same as abovementioned in the bacterial adhesion experiment. Thereafter, the $E$. coli or $S$. epidermidis biofilms on different membrane samples were stained with SYTO 63 for $10 \mathrm{~min}$ and then washed with a $0.9 \%$ $\mathrm{NaCl}$ solution. The samples were observed by CLSM, and a laser was set at $638 \mathrm{~nm}$ to detect fluorescence. For the analysis of the biofilms of $E$. coli and $S$. epidermidis mixture, the membranes were immersed in a $5 \mathrm{~mL}$ of bacterial suspension mixture $(1: 1)$ for contact for $12 \mathrm{~h}$ at $25^{\circ} \mathrm{C}$ and $37^{\circ} \mathrm{C}$, respectively. After this, the membranes were taken out and rinsed with the $0.9 \% \mathrm{NaCl}$ solution. Then, the samples were dyed using the Gram Stain Kit L7005 (volume of solutions A and B = 1 : 1) for 10 min and then washed with $0.9 \% \mathrm{NaCl}$ solution. The samples were observed by CLSM using an excitation laser at $488 \mathrm{~nm}$ to measure green fluorescence at $500 \mathrm{~nm}$ emission for Gram-negative bacteria and red fluorescence at $625 \mathrm{~nm}$ emission for the Gram-positive bacteria. The volume and structure of the biofilm were analyzed using the Imaris 8.1.2 software (software for 3D and 4D realtime interactive data visualization and management).

\section{Dynamic membrane fouling analysis via microfiltration}

Cross-flow microfiltration was carried out with an E. coli suspension $\left(10^{7}\right.$ cells per $\left.\mathrm{mL}\right)$ via several cycles of foulingwashing to study the dynamic formation of biofouling. The effective area of the filtration module was $3.8 \mathrm{~cm}^{2}$. First, the system was filtered with distilled water for $1 \mathrm{~h}$ under a pressure of 1 bar to ensure a steady state. The flux was determined by the following equation:

$$
J=\frac{V}{A \times t}
$$

where $J$ is the flux, $V$ is the total volume of the permeate, $A$ is the effective area of the filtration membrane, and $t$ is the test time. The value of $J_{\mathrm{w} 1}$ was determined after $1 \mathrm{~h}$ filtration with pure water. After this, filtration of the $E$. coli suspension was conducted at a flow rate of $300 \mathrm{~mL} \mathrm{~min}^{-1}$ and a pressure of 1 bar for $0.5 \mathrm{~h}$, and the flux $J_{\mathrm{p}}$ was determined every $5 \mathrm{~min}$. Thereafter, the membrane was washed and cleaned thoroughly using water for $1 \mathrm{~h}$, and then, the flux was determined and obtained as $J_{\mathrm{w} 2}$. All the filtration experiments were carried out at $25^{\circ} \mathrm{C}$. The flux recovery ratio (FRR) and fouling resistance ratios $\left(R_{\mathrm{t}}, R_{\mathrm{r}}\right.$, and $\left.R_{\mathrm{ir}}\right)$ were calculated via the following equations: ${ }^{22-24}$

$$
\begin{gathered}
\mathrm{FRR}=\frac{J_{\mathrm{w} 2}}{J_{\mathrm{w} 1}} \times 100 \% \\
R_{\mathrm{r}}=\frac{J_{\mathrm{w} 2}-J_{\mathrm{p}}}{J_{\mathrm{w} 1}} \times 100 \% \\
R_{\mathrm{ir}}=\frac{J_{\mathrm{w} 1}-J_{\mathrm{w} 2}}{J_{\mathrm{w} 1}} \times 100 \% \\
R_{\mathrm{t}}=R_{\mathrm{r}}+R_{\mathrm{ir}}
\end{gathered}
$$

where total fouling resistance ratio $\left(R_{\mathrm{t}}\right)$ is usually used to evaluate the antifouling ability of a membrane and is divided into a reversible fouling ratio $\left(R_{\mathrm{r}}\right)$ and an irreversible fouling ratio $\left(R_{\mathrm{ir}}\right){ }^{23,24} R_{\mathrm{r}}$ is described as the recoverable decrease in flux owing to the deposition of foulant on the membrane surface and cake layer, whereas $R_{\mathrm{ir}}$ represents irreversible fouling that results from the clogging of pores and adsorption of foulant in the inner membrane pores. High FRR values or low $R_{\text {ir }}$ values represent better antifouling ability.

In addition, the fouling test was performed by dynamic filtration using synthetic wastewater at 1 bar and $25^{\circ} \mathrm{C}$. First, the stable water flux was determined and obtained for filtration with pure water for $0.5 \mathrm{~h}$ after pre-filtration for $1 \mathrm{~h}$. Second, the feed solution was replaced with synthetic wastewater, and the flux was obtained as $J_{\mathrm{p}}$ during filtration for $1 \mathrm{~h}$. Third, the membrane filtration system was washed using pure water for $1 \mathrm{~h}$, and then, filtration was conducted with pure water for $0.5 \mathrm{~h}$ again, and one cycle was completed. The synthetic wastewater consisted of $0.3 \mathrm{~g} \mathrm{~L}^{-1}$ BSA, $9 \mathrm{mM} \mathrm{L}^{-1} \mathrm{NaCl}, 2 \mathrm{mM} \mathrm{L}^{-1} \mathrm{NaHCO}_{3}, 1 \mathrm{mM} \mathrm{L}^{-1} \mathrm{CaCl}_{2}$, and $1 \mathrm{mg}$ $\mathrm{L}^{-1}$ humic acid (HA), ${ }^{25-27}$ and a suspension of this mixture was used as the filtration feed after natural sedimentation for $2 \mathrm{~h}$. Dynamic fouling analysis was also carried out via several cycles of the fouling-washing process at different temperatures using synthetic wastewater filtration. The fouling-washing process was similar to that in the filtration experiments of the bacterial suspension, whereas the fouling process was conducted at $37{ }^{\circ} \mathrm{C}$ followed by cold water washing process at $15{ }^{\circ} \mathrm{C}$. As results, the flux recovery ratio (FRR) and fouling resistance ratios $\left(R_{\mathrm{r}}, R_{\mathrm{ir}}\right.$, and $R_{\mathrm{t}}$ ) were calculated via eqn (2), (3), (4), and (5), respectively.

\section{Results and discussion}

\section{Study of anti-biofouling properties of membranes using Gram-negative and Gram-positive bacteria}

The antimicrobial properties of the membranes were determined via bacterial adhesion of Gram-negative $E$. coli and Gram-positive $S$. epidermidis in this study. For the $E$. coli test, Fig. 1 showed that significantly fewer bacteria were observed on 


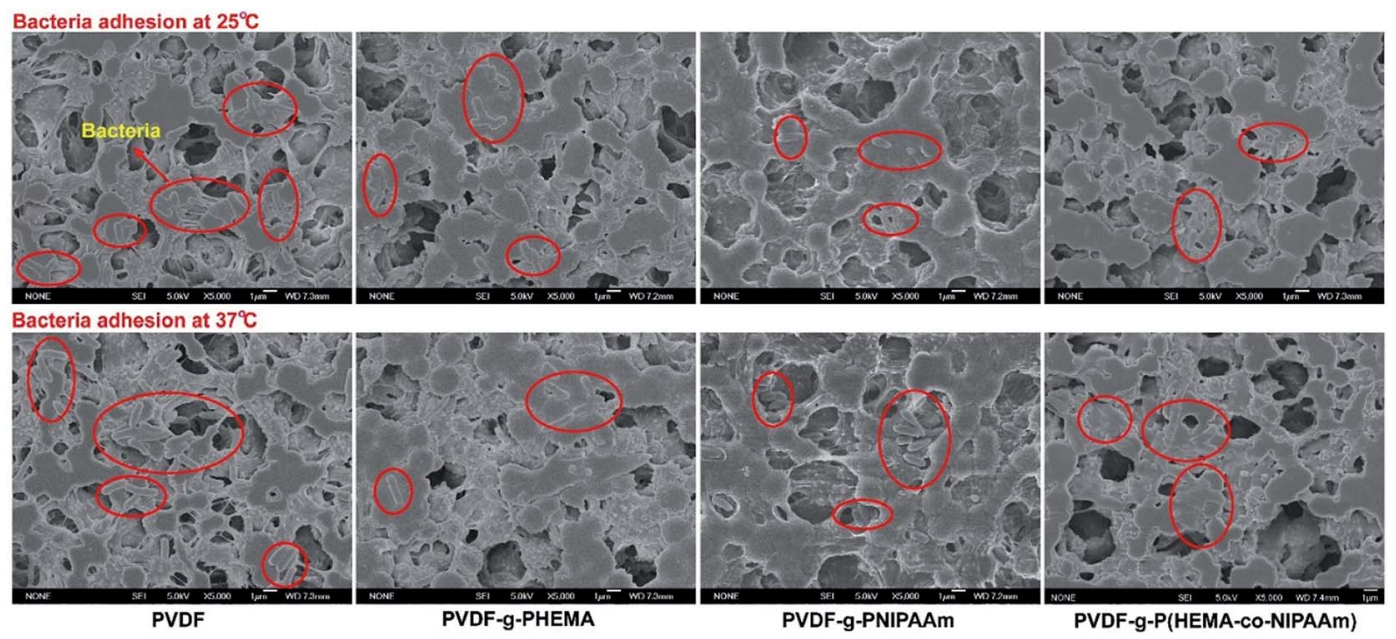

Fig. 1 SEM images of adhesion of Escherichia coli on different membrane surfaces at $25^{\circ} \mathrm{C}$ and $37^{\circ} \mathrm{C}$.

the modified membranes than those on the pristine PVDF membrane. More specifically, lower values of bacterial adhesion were observed on the PVDF- $g$-PNIPAAm and PVDF- $g$-P(HEMAco-NIPAAm) membranes at $25{ }^{\circ} \mathrm{C}$, with the reduction of $67 \%$ and $71 \%$, respectively, in comparison with that for the original PVDF membrane; this was a good indication of high resistance to bacterial adhesion on these modified membranes. It is known that bacteria readily adhere to hydrophobic surfaces via hydrophobic-hydrophobic interactions between their cell wall and the membrane surface. In general, water molecules were repulsed away from the original PVDF membrane surface owing to the absence of hydrogen bonding interactions in the boundary layer between the hydrophobic membrane interface and water; this enabled the bacteria to approach the boundary layer and adhere to the membrane. On the other hand, a hydration layer tends to appear on the hydrophilic-modified membranes through hydrogen bonding interactions between water and the membrane interface, and the hydration layer prevents bacteria from adhering to the membrane and further getting deposited on the surface. ${ }^{28}$ Hence, the modified membranes with high hydrophilicity exhibited antimicrobial properties. The E. coli release activity was also confirmed by the CFU tests, as shown in Fig. 2. The results indicated that the remaining amounts of bacteria adhering to the modified membranes after detachment at $25^{\circ} \mathrm{C}$ were obviously less than those in the groups treated at $37^{\circ} \mathrm{C}$, indicating good biofouling release ability owing to thermosensitive properties. Moreover, after bacterial release at $25{ }^{\circ} \mathrm{C}$, much fewer bacterial colonies were observed on the plate with the PVDF- $g$-P(HEMA-coNIPAAm) membrane in comparison with those for the original and PNIPAAm membranes; this was mainly due to not only the increase in the fouling resistance of the copolymer-modified membrane at $37{ }^{\circ} \mathrm{C}$ upon grafting PHEMA (less bacterial attachment on the copolymer-modified membrane before detachment) but also the improvement in fouling release in response to changes in temperature upon grafting PNIPAAm.

The adhesion of S. epidermidis to the membranes was also observed by SEM, and the results are shown in Fig. 3. It can clearly be seen that fewer bacteria were observed on the modified membranes in comparison with those on the original membrane at both $25^{\circ} \mathrm{C}$ and $37^{\circ} \mathrm{C}$; this indicated better antifouling property of the modified membrane, and the results were similar to those of the E. coli attachment test (Fig. 1). However, the amounts of $S$. epidermidis attached to the PNIPAAm and copolymer-modified membranes at $25{ }^{\circ} \mathrm{C}$ were roughly the same as in the groups treated at $37{ }^{\circ} \mathrm{C}$, and the results were different from those for the adhesion of $E$. coli at different temperatures. Through comparison of the original and modified membranes, it was observed that hydrophilicity had a significant effect on the fouling resistance; however, via comparison of the modified membranes at different temperatures in the S. epidermidis tests, it was observed that tunable hydrophilicity caused by thermosensitive properties slightly affected the fouling resistance. In Venault's study, ${ }^{18}$ it was reported that both E. coli and S. epidermidis favored pristine and hydrophobic PVDF surfaces more than those of the modified membranes blended with hydrophilic functional polymers, with over $99 \%$ reduction of bacterial attachment on the modified membranes. It can be seen from Fig. 4 that bacterial colonies on the plates of the modified membranes are visibly fewer than those on the plates of the original membrane after bacterial detachment for $5 \mathrm{~h}$, whereas there is no obvious difference in the biofouling release with respect to the same modified membrane at different temperatures; this suggests that the thermosensitive properties slightly influence the release of $S$. epidermidis.

Moreover, other Gram-positive bacteria, except S. epidermidis, can be used to evaluate the antifouling properties of the modified thermosensitive membranes in future studies. In a previous study, ${ }^{20}$ Wang et al. designed a low-fouling RO membrane via surface modification by grafting a zwitterionic polymer, and two model microorganisms, namely, E. coli and Bacillus subtilis (Gram-positive bacterium), were utilized to examine the antimicrobial properties of the membrane. They reported that bacterial mortality for the modified membrane was nearly $100 \%$ for both E. coli and B. subtilis, which suggested strong antimicrobial properties of the modified membrane against Gram-negative and 

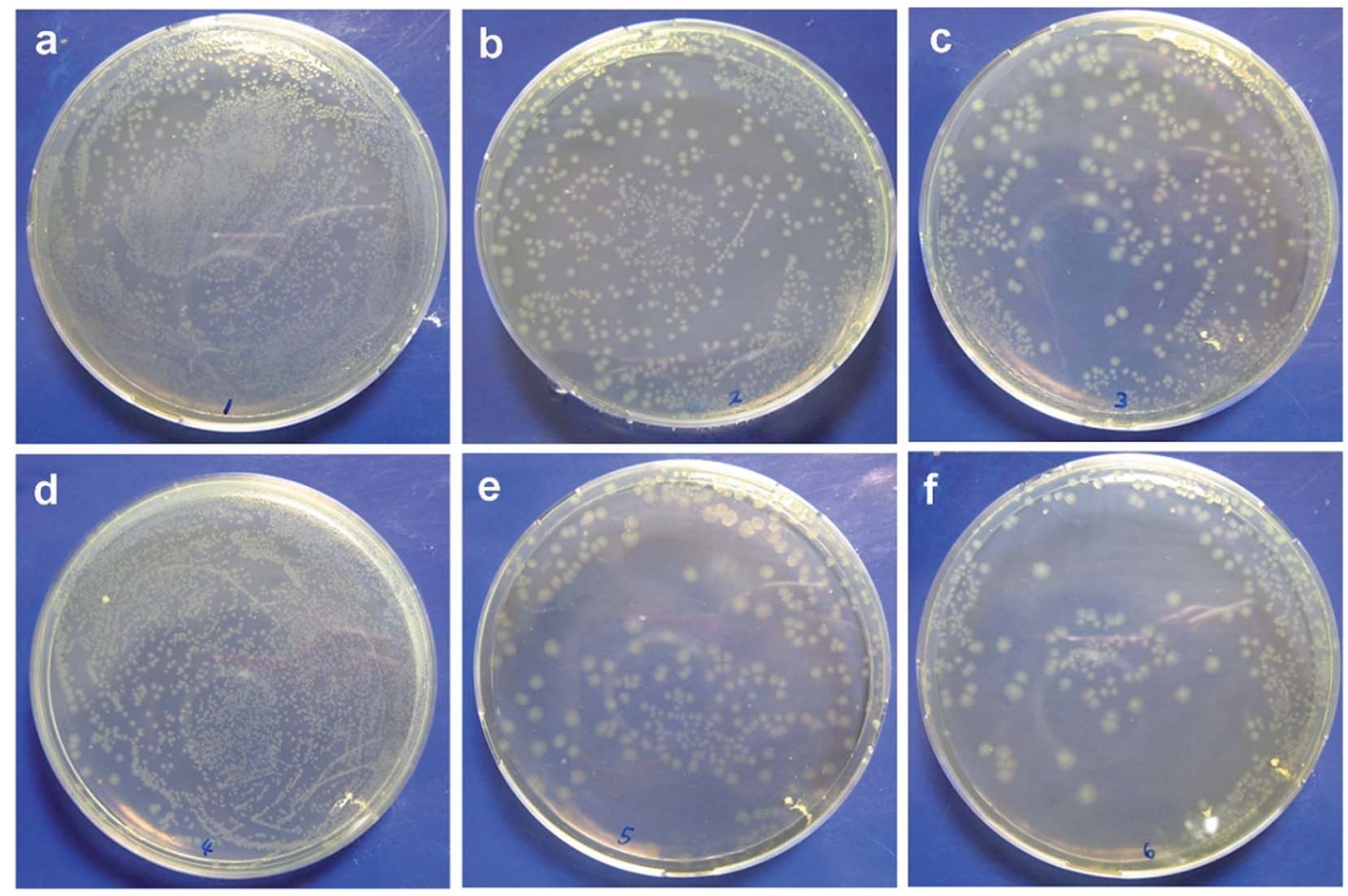

Fig. 2 (a-c) E. coli colonies after detachment at $37^{\circ} \mathrm{C}$ observed on PVDF, PVDF- $g$-PNIPAAm, and PVDF-g-P(HEMA-co-NIPAAm) membranes, respectively; $(\mathrm{d}-\mathrm{f}) \mathrm{E}$. coli colonies after detachment at $25^{\circ} \mathrm{C}$ observed on PVDF, PVDF-g-PNIPAAm, and PVDF-g-P(HEMA-co-NIPAAm) membranes, respectively.
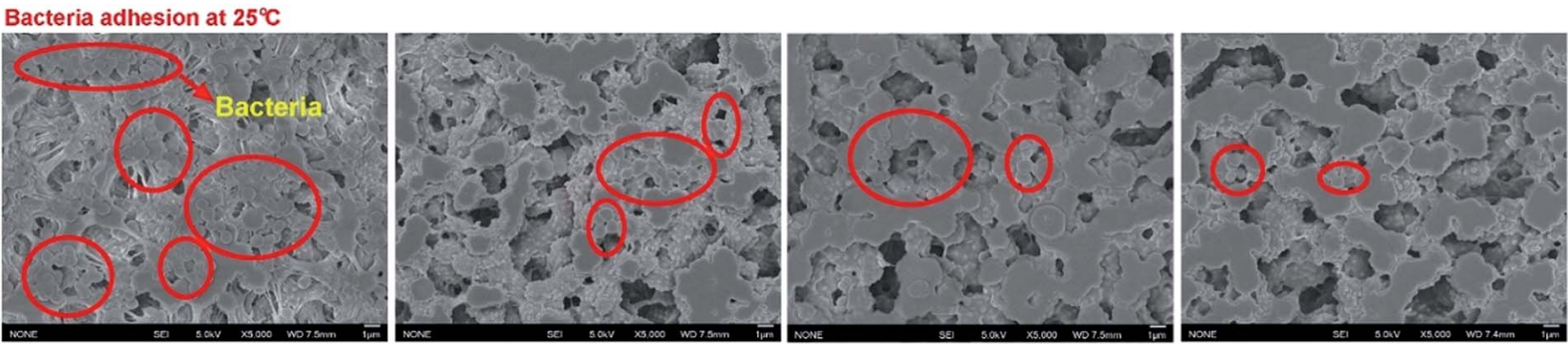

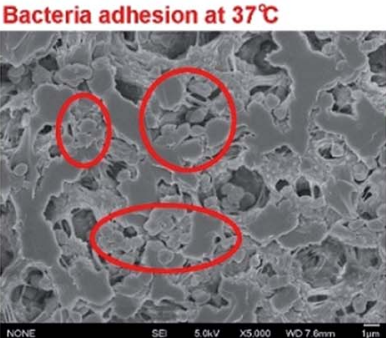

PVDF

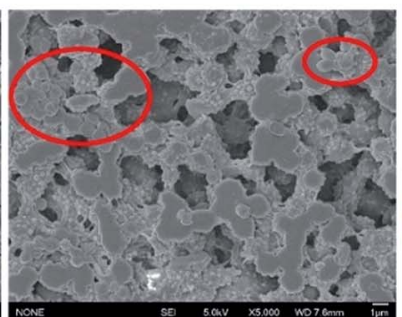

PVDF-g-PHEMA

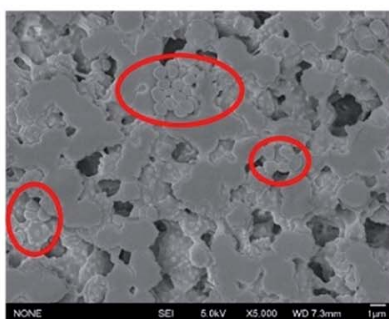

PVDF-g-PNIPAAm

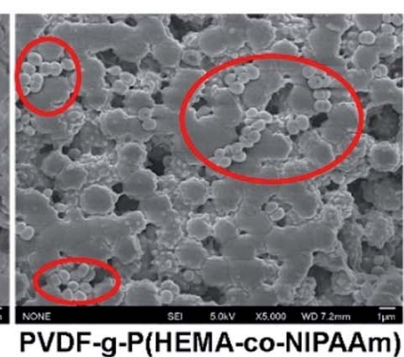

Fig. 3 SEM images of adhesion of Staphylococcus epidermidis to different membrane surfaces at $25^{\circ} \mathrm{C}$ and $37^{\circ} \mathrm{C}$.

Gram-positive bacteria. Xu et $a .^{19}$ prepared an antimicrobial polysulfone membrane blended with $\mathrm{Ag} / \mathrm{Cu}_{2} \mathrm{O}$ hybrid nanowires, and the blended membrane exhibited excellent antibacterial performance against both Gram-negative E. coli and Grampositive Staphylococcus aureus. SEM images also indicated that the adhesion of $E$. coli and $S$. aureus to the blended membrane was hindered, and their growth was also remarkably inhibited on the modified surface.

\section{Study of the formation and structure of biofilms on the} membranes with CLSM

Study of the formation and structure of biofilms using mono-species. To further study biofouling and the influences of bacterial species and membrane properties on its structure, we visibly detected and analyzed biofilms via confocal microscopy using the attachment of E. coli and S. epidermidis, and the 

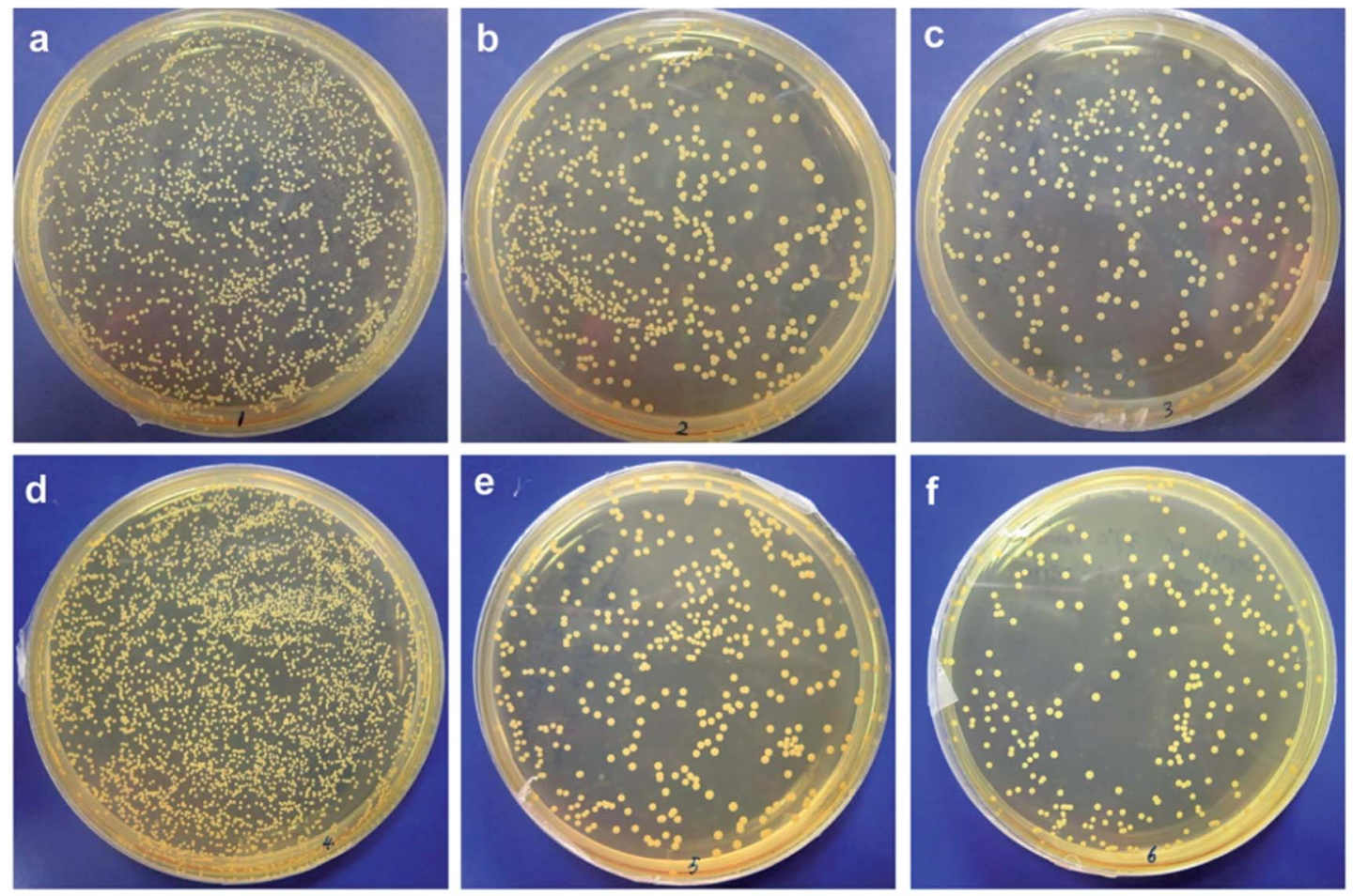

Fig. 4 (a-c) S. epidermidis colonies after detachment at $25^{\circ} \mathrm{C}$ observed on PVDF, PVDF-g-PNIPAAm, and PVDF- $g$-P(HEMA-Co-NIPAAm) membranes, respectively; (d-f) S. epidermidis colonies after detachment at $37^{\circ} \mathrm{C}$ observed on PVDF, PVDF-g-PNIPAAm, and PVDF- $g$-P(HEMAco-NIPAAm) membranes, respectively.

results of the confocal analysis are displayed in Fig. 5. The structure of the biofilm on the pristine membrane was quite different from those on the modified membranes for both $E$. coli and $S$. epidermidis. Specifically, in the E. coli adhesion test, a thick biofilm layer covered the original membrane surface, with a thickness of 31.2 and $35.1 \mu \mathrm{m}$ at $37{ }^{\circ} \mathrm{C}$ and $25{ }^{\circ} \mathrm{C}$, respectively, whereas small pieces of the biofilm were scattered over the surface of the PVDF- $g$-P(HEMA-co-NIPAAm) membrane, with a thickness of 27.3 and $23.4 \mu \mathrm{m}$ at $37^{\circ} \mathrm{C}$ and $25^{\circ} \mathrm{C}$, respectively. The results demonstrated that the modified membranes with hydrophilic surfaces exhibited high resistance towards the attachment of $E$. coli and the formation of biofilms. Quantitative analysis also confirmed that the minimum volume of the E. coli biofilm was found on the PVDF- $g$-P(HEMA-coNIPAAm) membrane at an attachment temperature of $25{ }^{\circ} \mathrm{C}$; this proved its excellent anti-biofouling and thermosensitive properties. Thus, the formation of a biofilm by Gram-negative $E$. coli on the membrane surface was effectively inhibited after the functional polymers were grafted, and the structure of the biofilm was also affected by the hydrophilicity of the membrane. In addition, it is inferred that the thick biofilm layer on the pure PVDF membrane is difficult to be released and removed via hydraulic cleaning owing to its high thickness and strong interaction with the membrane through a large contact area; however, the scattered pieces of biofouling on the PVDF- $g$ $\mathrm{P}$ (HEMA-co-NIPAAm) membrane are expected to be easily released and removed via cleaning. Moreover, according to an AFM analysis conducted in our previous study, ${ }^{14}$ the modified membranes exhibited a smoother surface structure than the unmodified membrane; this led to the formation of less biofouling on the modified membrane because bacteria usually prefer to adhere to rough surfaces. ${ }^{18}$ Hence, the structure/ morphology (roughness) of the membrane also plays an important role in the formation of biofouling.

It can also be seen from Fig. 5 that the structure of the $S$. epidermidis biofilm was very similar to that formed by $E$. coli, such that an integrated and thick layer of biofouling formed on the surface of the original membrane, whereas biofouling spots scattered over the surface of the modified membranes. In addition, no obvious difference in the volumes of the biofilms on the modified membranes was found in the tests performed at different temperatures; this suggested that the effect of thermosensitive properties on the adhesion of $S$. epidermidis was not significant, which was consistent with previous results. It is worth noting that bacterial adhesion is also strongly dependent on the properties of the bacterial species. For example, different cell walls and compositions of the EPSs produced affect the interaction with the membrane materials. It was reported by Carretier et al. ${ }^{29}$ that different amounts of bacterial adhesion were found on the same membrane in the Gram-negative E. coli tests and Gram-positive Streptococcus mutans tests owing to the different nature of the bacterial species.

Study of the formation and structure of biofilms using a mixture of species. To study the effect of bacterial species on biofouling and the mutual interaction of bacterial species, the 


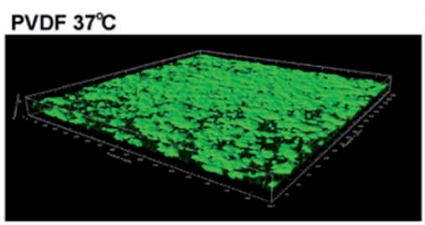

PVDF-g-PHEMA $37^{\circ} \mathrm{C}$

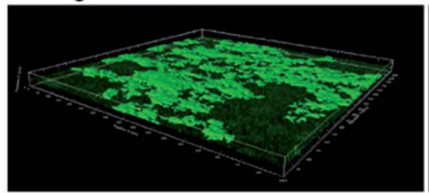

PVDF-g-PNIPAAM $37^{\circ} \mathrm{C}$

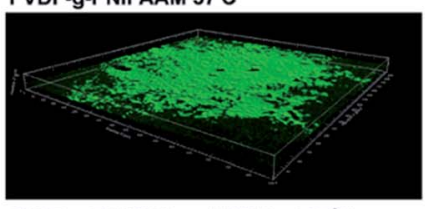

PVDF-g-P(HEMA-Co-NIPAAm) $37^{\circ} \mathrm{C}$

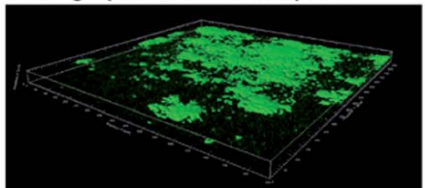

PVDF $25^{\circ} \mathrm{C}$

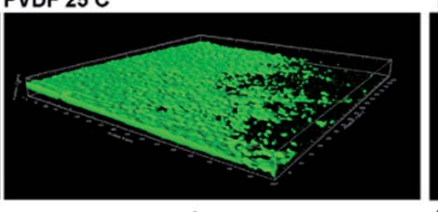

PVDF-g-PHEMA $25^{\circ} \mathrm{C}$

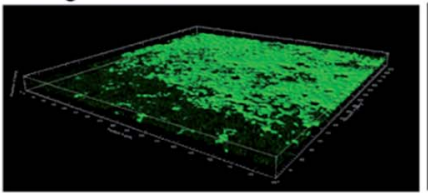

PVDF-g-PNIPAAm $25^{\circ} \mathrm{C}$

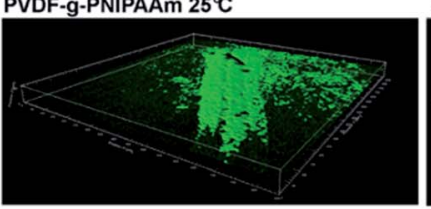

PVDF-g-P(HEMA-CO-NIPAAm) $25^{\circ} \mathrm{C}$

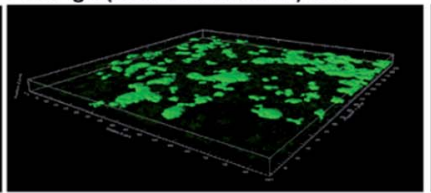

PVDF $37^{\circ} \mathrm{C}$

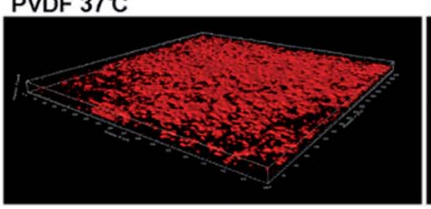

PVDF-g-PHEMA $37^{\circ} \mathrm{C}$

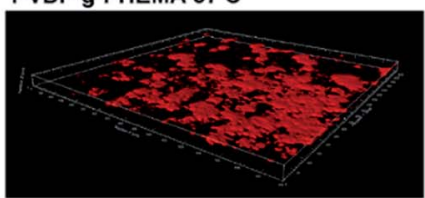

PVDF-g-PNIPAAm $37^{\circ} \mathrm{C}$

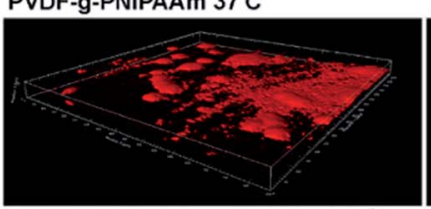

PVDF-g-P(HEMA-Co-NIPAAm) $37^{\circ} \mathrm{C}$

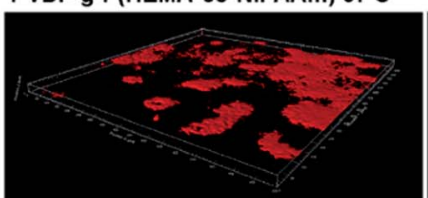

PVDF $25^{\circ} \mathrm{C}$

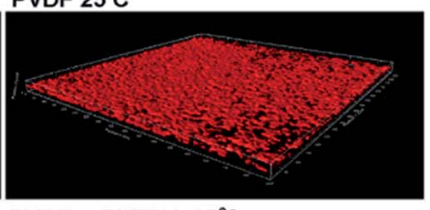

PVDF-g-PHEMA $25^{\circ} \mathrm{C}$

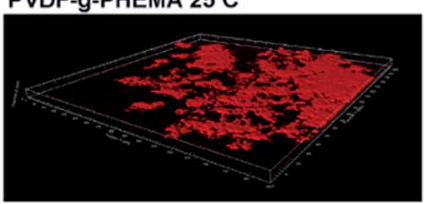

PVDF-g-PNIPAAm $25^{\circ} \mathrm{C}$

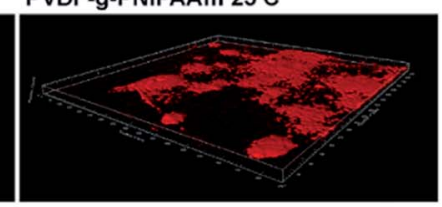

PVDF-g-P(HEMA-Co-NIPAAm) $25^{\circ} \mathrm{C}$

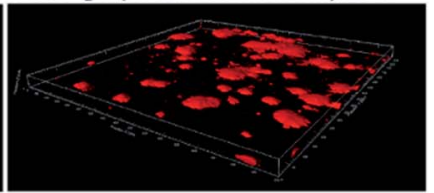

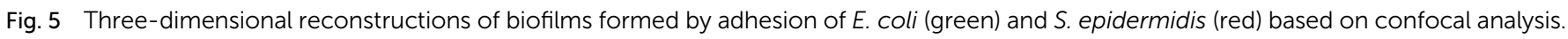

simultaneous development of biofouling and the biofilm structure of the mixture of the two model species were subsequently investigated via confocal observations. The 3D biofilm construction of a mixture of E. coli and S. epidermidis is shown in Fig. 6(a). For the original membrane, a thick biofilm layer of the mixed-species completely covered the membrane surface, and both bacterial species were uniformly present and intermixed with each other throughout the biofilm. Considering the modified membranes, biofouling of the mixed-species was markedly less than that for the original membrane, and each species preferentially assembled to form its own biofouling layer. The biofilm thickness was approximately 35.4, 30.4, 24.4, and $24.4 \mu \mathrm{m}$ for the PVDF, PVDF- $g$-PHEMA, PVDF- $g$-PNIPAAm, and PVDF- $g$-P(HEMA-co-NIPAAm) membranes, respectively, at $25{ }^{\circ} \mathrm{C}$, and the corresponding values were $33.7,28.4,28.4$, and $28.4 \mu \mathrm{m}$, respectively, at $37^{\circ} \mathrm{C}$. According to the quantitative analysis presented in Fig. 6(b), the total biofouling on the pure PVDF membrane was much greater than that on the modified membrane. In addition, in comparison with that of the monospecies, the total biofouling of mixed-species on the modified membranes was more severe under the same conditions; this suggested that the biofouling behavior of each species was influenced by the presence of other species. Therefore, the behavior and structure of biofouling are expected to be quite complicated in practical wastewater treatment in MBRs as the microbial communities and species in the sludge are rich and various, and the species would affect each other in terms of the biofouling behavior. ${ }^{30}$ Moreover, the structure of the biofilm was also influenced by the species such that a thin layer of biofouling was observed on the modified membranes for a mixture of the two species, whereas clusters/spots of bacteria were formed for the mono-species adhesion. It is inferred that a biofouling layer is more difficult to clean owing to its interaction with a larger surface area in comparison with a bacterial cluster. The types and characteristics, such as bacterial motility, type of the EPS produced, and interactions with other microorganisms, of microorganisms play a crucial role in the formation of biofilms on a membrane surface ${ }^{10}$ In this case, Liu reported that the biofouling tendency of Pseudomonas aeruginosa was found to be higher in comparison with that of $E$. coli owing to the differences in their characteristics. In addition, a thicker biofilm was formed in the presence of two model microorganisms in comparison with that for the mono-species owing to an enhancement in the attachment of $E$. coli in the presence of $P$. aeruginosa, which was similar to our observation. It is suggested that inter-bacterial adhesion, rather than direct contact with the substrate, promotes the progressive formation and maturation of biofilms, and it has been confirmed by a previous study that inter-bacterial adhesion enhances the formation of mixed biofilms. ${ }^{30}$

\section{Dynamic membrane fouling analysis via microfiltration}

Microfiltration using bacterial suspension. It is well known that activated sludge containing microbial cells plays a crucial role in the biodegradation of wastewater compounds during MBR operations, and biofouling is easily formed owing to the early attachment of biofoulants and their subsequent deposition on the membrane surface. Therefore, to investigate the decline in flux caused by biofouling on the original and copolymer-modified membranes, four cyclic filtration tests were carried out using an E. coli suspension as a pollutant feed followed by cleaning with water, and the results are displayed in Fig. 7. The flux underwent a fast and significant decline in the 

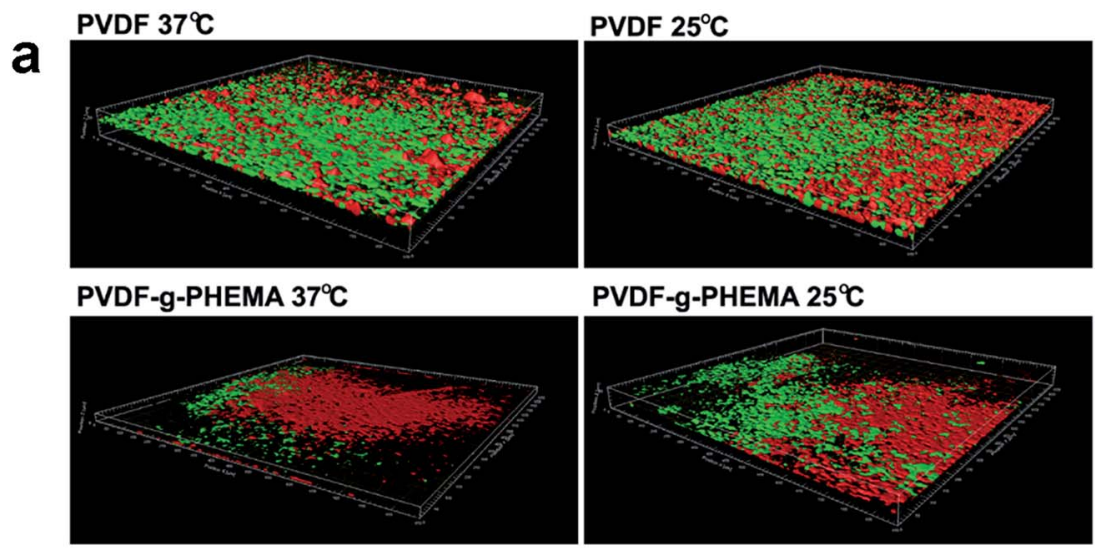

PVDF-g-PHEMA $25^{\circ} \mathrm{C}$
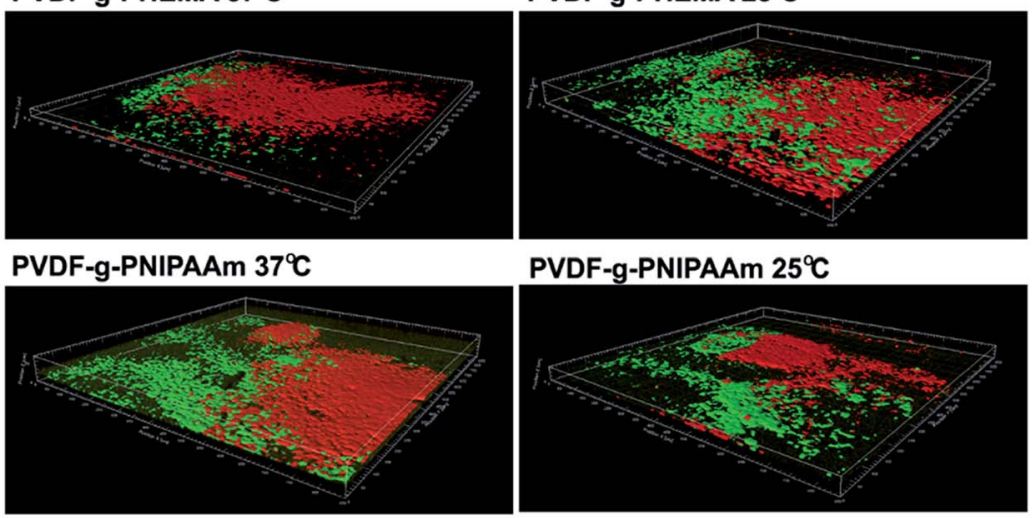

PVDF-g-PNIPAAm $25^{\circ} \mathrm{C}$
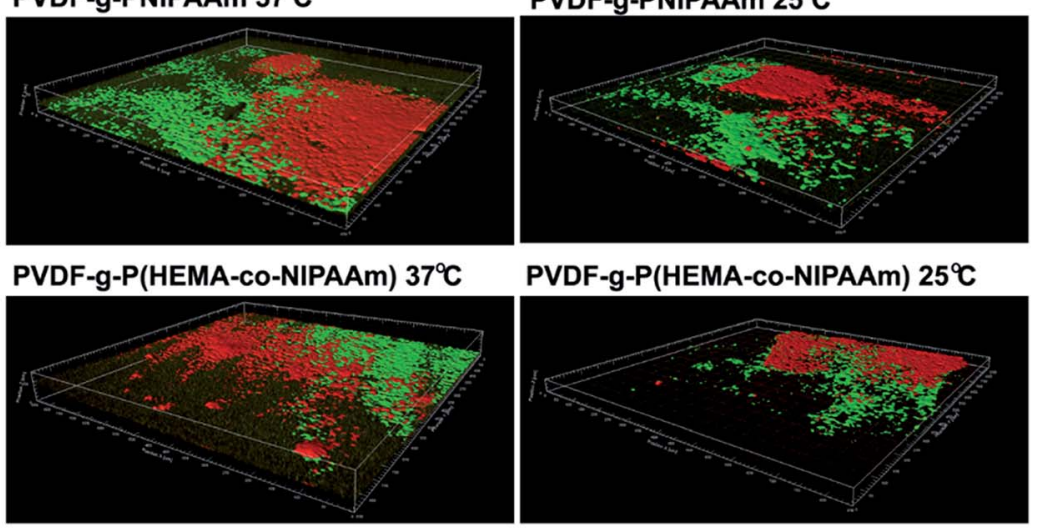

PVDF-g-P(HEMA-CO-NIPAAm) $25^{\circ} \mathrm{C}$

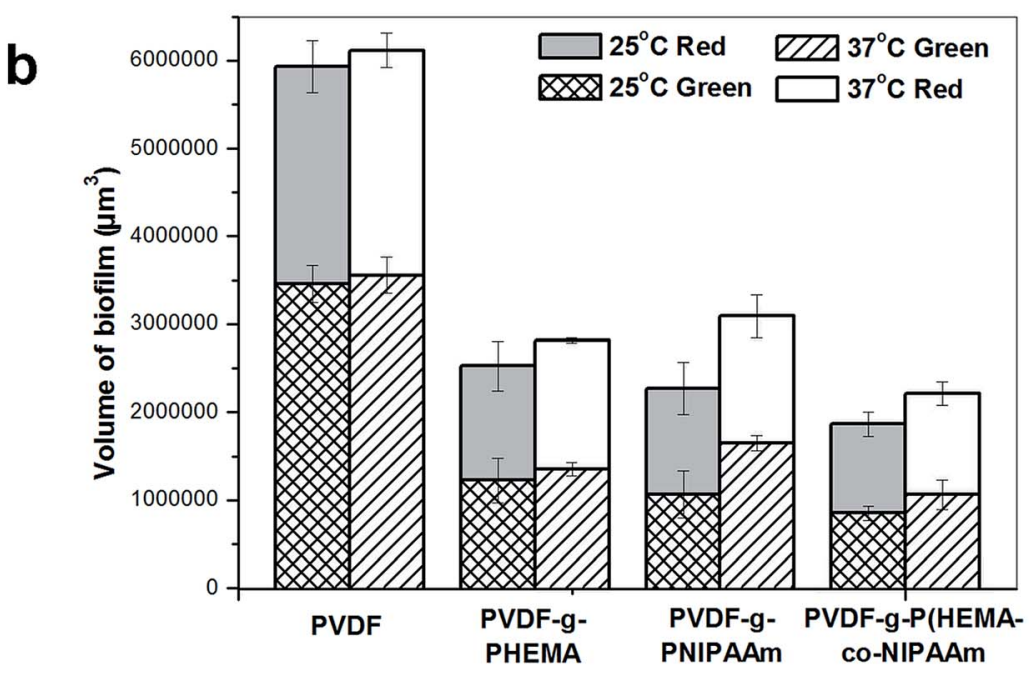

Fig. 6 (a) Three-dimensional reconstructions of biofilms formed by adhesion of E. coli and S. epidermidis based on confocal analysis; (b) quantitative analysis of the volumes of the mixed biofilms based on the 3D reconstructions.

beginning for both membranes, which was probably due to the deposition of bacteria on the surface and clogging of the pores, and the permeability of the PVDF-g-P(HEMA-co-NIPAAm) membrane was much higher than that of the pure PVDF membrane for each filtration cycle. In addition, Fig. 7(a) shows that the relative flux of the modified membrane always exceeded that of the original membrane, and the decline in flux for the modified membrane ranged from approximately $8 \%$ to $70 \%$ for the last three cycles, whereas the flux decreased from around $63 \%$ to $83 \%$ for the original membrane. The results for the flux recovery ratio (FRR) and fouling ratio are shown in Fig. 7(b) and (c), respectively. The modified membrane always exhibited a higher FRR value than the original PVDF membrane over the three filtration cycles, which corresponded to more severe bacterial fouling on the pure PVDF membrane. The reversible fouling ratio of the pure PVDF membrane decreased with the filtration runs and declined to zero after three filtration cycles, whereas a higher reversible fouling ratio and lower irreversible fouling ratio were observed for the modified membrane; this demonstrated that a large proportion of biofouling could be 

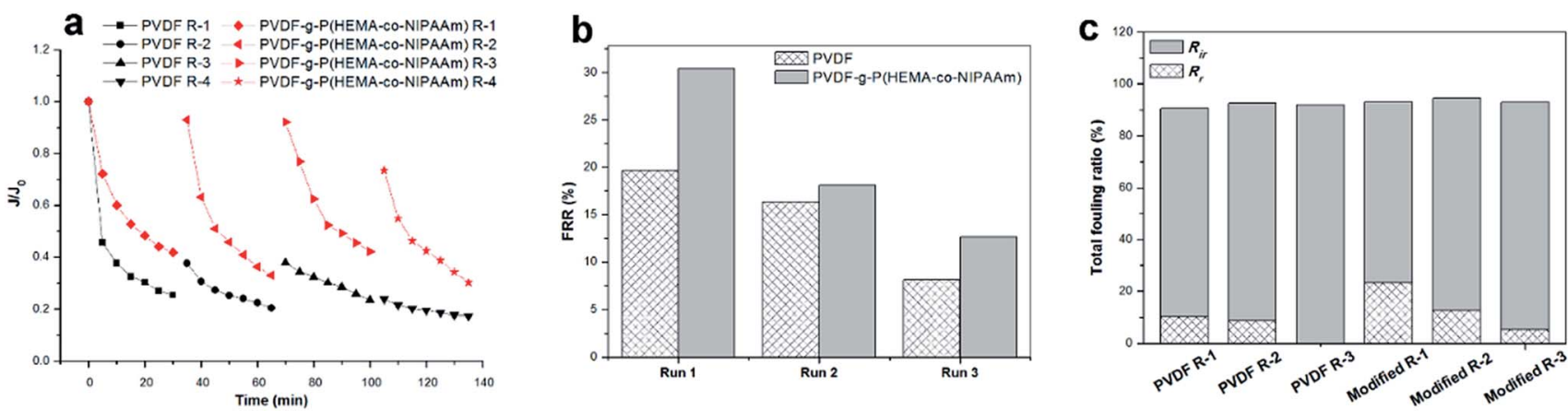

Fig. 7 (a) Relative flux through unmodified and modified membranes for filtration of a bacterial suspension at $25^{\circ} \mathrm{C}$ over four fouling-cleaning cycles; (b) flux recovery ratio of the membranes; (c) fouling ratio of the membranes ( $R_{\mathrm{r}}$ : reversible fouling ratio, $R_{\mathrm{ir}}$ : irreversible fouling ratio). Run 1 of the fouling-washing process is indicated by R-1 in the legend.

removed via cleaning with water after P(HEMA-co-NIPAAm) was grafted. However, the maximum FRR value for filtration was approximately $30 \%$, much less than that for the filtration of BSA measured in our previous study $;{ }^{14}$ this was probably due to the formation of a dense cake layer and the blocking of pores by bacteria with large sizes. Therefore, it is inferred that backflushing can effectively remove bacterial fouling to improve the flux recovery, which can be performed in future studies. It was reported by Vanysacker et al. ${ }^{10}$ that the effect of the membrane type and microorganism species on the formation of biofilms was examined via a filtration operation on polyethylene (PE), polysulfone (PSF), and PVDF membranes using a suspension of E. coli and/or Pseudomonas aeruginosa as a pollutant feed, and the results showed that the relative permeability decreased with fluctuation between $55 \%$ and $85 \%$ after $24 \mathrm{~h}$ operation due to biofouling. It has also been reported that a greater extent of blockage of internal pores by bacterial cells easily occurs for membranes with large pores, ${ }^{31}$ and the PVDF membrane used in this study is exactly similar to these membranes.

Microfiltration using synthetic wastewater. In wastewater treatment in MBRs, the sewage feed usually contains many types of foulant such as proteins, humic substances, and inorganic ions. Therefore, in this study, synthetic wastewater was prepared with a pollutant solution containing three model foulants, i.e. BSA, humic acid (HA), and inorganic ions, $\mathrm{Ca}^{2+},{ }^{25-27}$ and a filtration experiment was carried out using this synthetic wastewater. Fig. 8(a) shows the fivefold concentrate solution of synthetic wastewater used in the filtration process. As shown in Fig. 8(b), the membranes became dark brown after permeation of synthetic wastewater; this indicated that fouling had formed on the membrane surface. This can be confirmed by the results displayed in Fig. 8(c) and (d). Specifically, although the permeation flux of the original and modified membranes both underwent a dramatic decline in the initial stage of filtration, the modified membrane always exhibited much higher permeability than the pristine membrane. Then, the flux of the membranes became relatively constant after 10 min filtration. Furthermore, as shown in Fig. 8(d), the modified membrane displayed a reversible fouling ratio as high as $27 \%$ and a lower irreversible fouling ratio of $25 \%$ in comparison with the unmodified membrane, for which the $R_{\mathrm{r}}$ value was only $9 \%$ and the $R_{\mathrm{ir}}$ value was as high as $45 \%$. The lower irreversible fouling ratio demonstrated that the fouling resistance was enhanced, and the higher reversible fouling ratio suggested that foulants were readily released and removed probably due to the breakage of weak interactions between the foulants and the modified surface. ${ }^{32}$ It has been mentioned that high hydrophilicity is able to decrease the adhesion forces between typical organic pollutants and the hydrophilic surface of modified membranes. ${ }^{33,34}$ Moreover, the FRR value of the pure PVDF membrane was only $55 \%$, whereas the FRR value of the PVDF- $g$ P(HEMA-co-NIPAAm) membrane increased to $75 \%$. A cake layer was easily formed in the microfiltration process using synthetic wastewater containing multiple foulant compounds, ${ }^{35}$ and, in particular, the complexation of pollutants usually occurred in the presence of $\mathrm{Ca}^{2+}$, which further promoted the formation of a cake layer and aggravated membrane fouling. ${ }^{27}$ Thus, the flux was not easily fully recovered via simple hydraulic cleaning.

To investigate the fouling release ability exhibited by the thermosensitive membranes prepared in this study, three filtration cycles were conducted using synthetic wastewater, and one cycle process consisted of $0.5 \mathrm{~h}$ pollutant filtration at $37^{\circ} \mathrm{C}$, followed by cleaning with cold water for $1 \mathrm{~h}$ at $15^{\circ} \mathrm{C}$. Fig. 9(a) clearly shows that the modified membrane had higher permeability than the pure PVDF membrane. Fig. 9(b) shows that the modified membrane exhibits an FRR value as high as $94 \%$, whereas the value is only $70 \%$ for the original membrane after the first cycle; this demonstrated that the flux of the modified membrane was very easily recovered by cold water cleaning. It was found from Fig. 9(c) that higher reversible fouling was deposited on the modified membrane and further cleaned by flushing with cold water in comparison with that on the pristine membrane; this proved that the fouling release ability of the modified membrane was higher owing to its tunable hydrophilicity in response to changes in temperature. However, the FRR value of the modified membrane decreased to $41 \%$ after three filtration cycles. This phenomenon was probably due to two reasons. First, progressive fouling was formed on the membrane surface during consecutive filtration runs. Second, as abovementioned in the discussion, a dense cake layer easily formed in the presence of $\mathrm{Ca}^{2+}$ and other multiple pollutants, which led to heavy membrane fouling, and internal fouling 

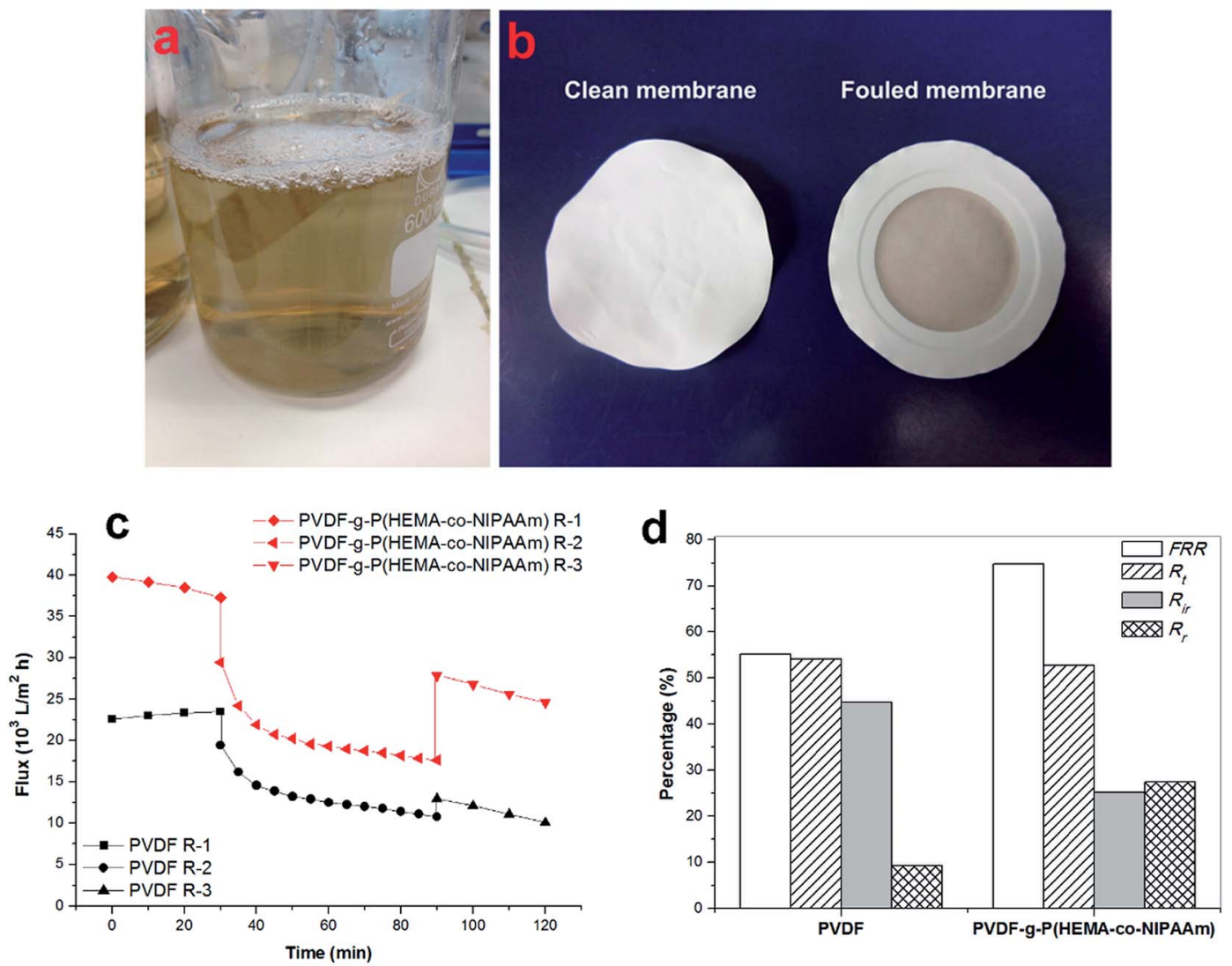

Fig. 8 (a) Image of fivefold concentrate of synthetic wastewater; (b) images of modified membrane before and after use for wastewater filtration; (c) time-dependent flux and (d) dynamic fouling test of membranes using filtration of synthetic wastewater at $25^{\circ} \mathrm{C}$ (FRR: flux recovery ratio, $R_{\mathrm{t}}$ : total fouling resistance ratio, $R_{\mathrm{r}}$ : reversible fouling ratio, $R_{\mathrm{ir}}$ : irreversible fouling ratio). The entire filtration process consisted of three steps: filtration of pure water, filtration of synthetic wastewater (flux decline), followed by filtration of pure water again after hydraulic washing (flux recovery). The first step of this process is indicated by $\mathrm{R}-1$ in the legend.
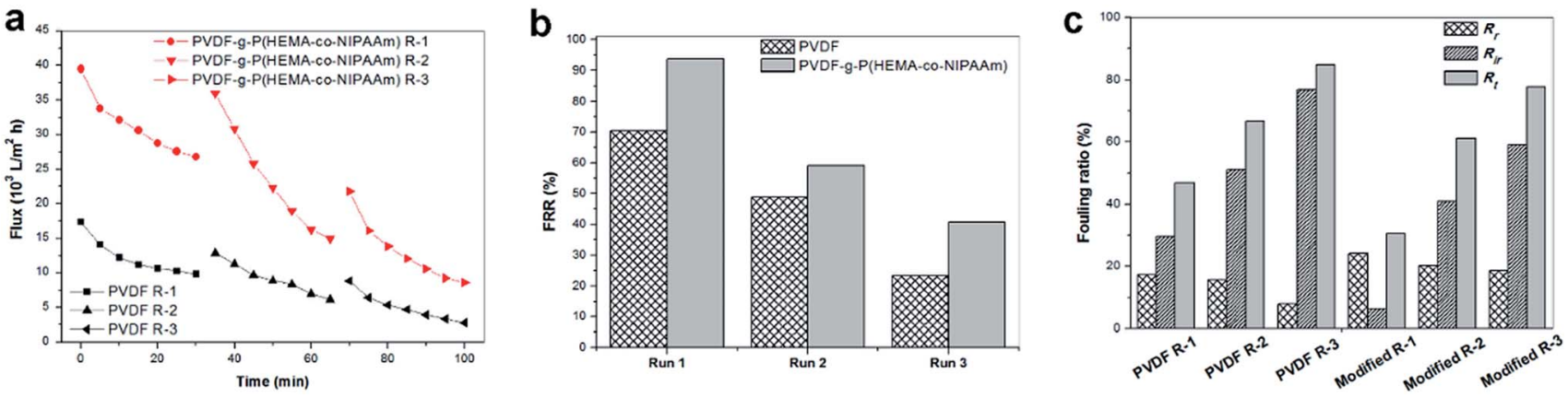

Fig. 9 (a) Flux through membranes over three fouling-cleaning cycles, of which one cycle comprised filtration of synthetic wastewater at $37^{\circ} \mathrm{C}$ followed by cleaning with cold water at $15^{\circ} \mathrm{C}$; (b) flux recovery ratio and (c) fouling ratio of membranes $\left(R_{\mathrm{t}}\right.$ : total fouling resistance ratio, $R_{\mathrm{r}}$ : reversible fouling ratio, $R_{\mathrm{ir}}$ : irreversible fouling ratio). Run 1 of the fouling-washing process is indicated by R-1 in the legend.

might even occur in this case. Thus, other multiple cleaning methods can be employed in combination with hydraulic cleaning below the LCST of PNIPAAm to promote the removal of fouling in practical filtration processes for long-term operation. In a literature review, ${ }^{35} \mathrm{Wang}$ et al. stated that according to the fouling removal mechanisms, membrane cleaning strategies can be divided into four types: physical, chemical, physicochemical, and biological/biochemical cleaning. In addition, the time interval for in situ cleaning in MBRs is usually once every $10 \mathrm{~min}$ or several weeks or months depending on the fouling conditions and cleaning methods used, and its frequency is much higher than that of ex situ cleaning. Therefore, for thermosensitive membranes hydraulic cleaning with temperature control provides an auxiliary and feasible strategy for promoting fouling release and enhancing flux recovery in combination with classical cleaning methods for wastewater treatment in MBRs. 


\section{Conclusion}

In this study, the formation and structure of biofilms were investigated via confocal observation using mono-species and mixed-species of Gram-negative $E$. coli and Gram-positive $S$. epidermidis. The results confirmed that the membrane properties (hydrophilicity and morphology/roughness) markedly affected the formation of biofouling such that the antifouling properties of the PVDF membrane were significantly improved after the hydrophilic polymers were grafted. Moreover, it was suggested that the microorganism species also played an essential role in the formation and structure of biofilms as the species influenced each other's bacterial adhesion and biofouling behavior. Less biofouling was observed on the modified hydrophilic membranes, with scattered biofouling spots for mono-species, but a thin layer structure of biofouling for the mixed-species was observed, whereas heavy biofouling covered the original membrane with a thick cake layer for both the mono-species and mixed-species. Moreover, the modified membranes exhibited higher fouling resistance during filtration of synthetic wastewater and higher flux recovery after hydraulic cleaning in comparison with the pure PVDF membrane. These results also revealed that the hydrophilicity of the membrane affected the structure of biofilms such that biofouling formed on the modified membranes was easily removed by flushing with water owing to the thin layer or cluster structure of the biofouling. Therefore, the contribution of this study lies in providing useful insights and indications on how to control and inhibit biofouling effectively in the future.

\section{Acknowledgements}

The authors acknowledge the financial support received from the Singapore National Research Foundation under its Environmental \& Water Technologies Strategic Research Program and administered by the Environment \& Water Industry Program Office (EWI) of the PUB (grant 1102-IRIS-08-08). We also thank the support received from the Nanyang Environment and Water Research Institute, Nanyang Technological University.

\section{References}

1 J. A. Howell, T. C. Arnot and W. Liu, Ann. N. Y. Acad. Sci., 2003, 984, 411-419.

2 F. Fan, H. Zhou and H. Husain, Water Res., 2005, 40, 205212.

3 K. Kimura, H. Hara and Y. Watanabe, Desalination, 2005, 178, 135-140.

4 A. Y. Hu and D. C. Stuckey, J. Environ. Eng., 2006, 132, 190198.

5 H. J. Lin, K. Xie, B. Mahendran, D. M. Bagley, K. T. Leung, S. N. Liss, et al., Water Res., 2009, 43, 3827-3837.

6 J. Luo, J. Zhang, X. Tan, D. McDougald, G. Zhuang, A. G. Fane, S. Kjelleberg, Y. Cohen and S. A. Rice, Biofouling, 2014, 30, 1093-1110.
7 J. W. Costerton, Z. Lewandowski, D. E. Caldwell, D. R. Korber and H. M. Lappin-Scott, Annu. Rev. Microbiol., 1995, 49, 711745.

8 A. Drews, C. H. Lee and M. Kraume, Desalination, 2006, 200, 186-188.

9 H. Nagaoka, S. Ueda and A. Miya, Water Sci. Technol., 1996, 34, 165-172.

10 L. Vanysacker, P. Declerck, M. R. Bilad and I. F. J. Vankelecom, J. Membr. Sci., 2014, 453, 394-401.

11 K. Fish, A. M. Osborn and J. B. Boxall, Sci. Total Environ., 2017, 593-594, 571-580.

12 C. Dreszer, A. D. Wexler, S. Drusova, T. Overdijk, A. Zwijnenburg, H.-C. Flemming, J. C. Kruithof and J. S. Vrouwenvelder, Water Res., 2014, 67, 243-254.

13 D. Saeki, Y. Nagashima, I. Sawada and H. Matsuyama, Colloids Surf., A, 2016, 506, 622-628.

14 G. Zhao and W. N. Chen, Appl. Surf. Sci., 2017, 398, 103-115. 15 H. Daims, M. W. Taylor and M. Wagner, Trends Biotechnol., 2006, 24, 483-489.

16 H. Ma, B. S. Hsiao and B. Chu, J. Membr. Sci., 2014, 452, 446-452. 17 L. K. Ista, S. Mendeza and G. P. Lopez, Biofouling, 2010, 26, 111-118.

18 A. Venault, Y. H. Liu, J. R. Wu, H. S. Yang, Y. Chang, J. Y. Lai, et al., J. Membr. Sci., 2014, 450, 340-350.

19 Z. Xu, S. Ye, G. Zhang, W. Li, C. Gao, C. Shen, et al., J. Membr. Sci., 2016, 509, 83-93.

20 J. Wang, Z. Wang, J. X. Wang and S. Wang, J. Membr. Sci., 2015, 493, 188-199.

21 J. Nikkola, X. Liu, Y. Li, M. Raulio, H. L. Alakomi, J. Wei, et al., J. Membr. Sci., 2013, 444, 192-200.

22 W. Chen, Y. Su, L. Zheng, L. Wang and Z. Jiang, J. Membr. Sci., 2009, 337, 98-105.

23 Y. Hao, A. Moriya, T. Maruyama, Y. Ohmukai and H. Matsuyama, J. Membr. Sci., 2011, 376, 247-253.

24 X. Chen, B. Zhao, P. Han, W. Fu and L. Chen, React. Funct. Polym., 2014, 84, 10-20.

25 Y. X. Shen, K. Xiao, P. Liang, J. Y. Sun, S. J. Sai and X. Huang, J. Membr. Sci., 2012, 415, 336-345.

26 S. Liang, G. Qi, K. Xiao, J. Sun, E. P. Giannelis, X. Huang, et al., J. Membr. Sci., 2014, 463, 94-101.

27 X. Zhao and C. Liu, J. Membr. Sci., 2016, 515, 29-35.

28 F. Liu, N. Awanis Hashim, Y. Liu, M. R. Moghaeh Abed and K. Li, J. Membr. Sci., 2011, 375, 1-27.

29 S. Carretier, L. A. Chen, A. Venault, Z. R. Yang, P. Aimar and Y. Chang, J. Membr. Sci., 2016, 510, 355-369.

30 K. Kjærgaard, M. A. Schembri, H. Hasman and P. Klemm, J. Bacteriol., 2000, 182, 4789-4796.

31 E. S. Tarleton and R. J. Wakeman, Chem. Eng. Res. Des., 1993, 71, 399-410.

32 X. Zhao, Y. Su, Y. Li, R. Zhang, J. Zhao and Z. Jiang, J. Membr. Sci., 2014, 450, 111-123.

33 X. Zhao, H. Xuan, Y. Chen and C. He, J. Membr. Sci., 2015, 494, 48-56.

34 A. Tiraferri, Y. Kang, E. P. Giannelis and M. Elimelech, ACS Appl. Mater. Interfaces, 2012, 4, 5044-5053.

35 Z. Wang, J. Ma, C. Y. Tang, K. Kimura, Q. Wang and X. Han, J. Membr. Sci., 2014, 468, 276-307. 